\title{
Spatial variation in female southern elephant seal mass change assessed by an accurate non-invasive photogrammetry method
}

\author{
MARTIN POSTMA, MARTHÁN N. BESTER and P.J. NICO DE BRUYN \\ Mammal Research Institute, Department of Zoology \& Entomology, University of Pretoria, \\ Private Bag X20, Hatfield 0028, South Africa \\ mpostma@zoology.up.ac.za
}

\begin{abstract}
Physically weighing large marine mammals sequentially over time has presented researchers with a logistical challenge and has severely limited sample sizes. Using a well-established photogrammetry method we developed a simple mathematical method to calculate accurate mass measurements at specific stages in the life cycle of a top marine predator. Female southern elephant seals $(n=23)$ at Marion Island were sampled sequentially using photogrammetry and three-dimensional models (based on each photogrammetry project) were built for estimation of body mass. Simple equations were applied to obtain mass at critical instances in their life cycle. Marion Island elephant seal mass data was compared to data obtained from physically weighed elephant seals from King George, South Georgia and Macquarie islands. Females from Marion Island are smaller, but their percentage lactation mass loss is similar to females from these other populations. The similarity of percentage mass loss during lactation between different female populations illustrates the accuracy and practicality of the photogrammetric method over a temporal scale. Photogrammetric mass estimation can be used alongside datasets of physically weighed animals and can greatly benefit ecology and life history studies.
\end{abstract}

Received 23 July 2012, accepted 7 December 2012, first published online 10 April 2013

Key words: breeding season, life history theory, methodology advancement, Mirounga leonina, moult, pelagic foraging

\section{Introduction}

The study of population dynamics and life history has long remained important in the field of ecology, with the major objective of studying and analysing individual animals of a population over space and time (Lebreton et al. 1992). Methods that simplify detection of life history traits over a temporal scale are of great value. A simpler non-invasive method for an important life history parameter (size) emerged through the use of photogrammetry, the science of making measurements from photographs (Baker 1960). One application that received much attention was the development of methods to estimate mass of some marine mammals (e.g. de Bruyn et al. 2009). The volumetric mass estimation method (de Bruyn et al. 2009) can greatly assist longitudinal studies (de Bruyn et al. 2008) that would traditionally have required reweighing of marked animals (e.g. Carlini et al. 1999).

Chemical immobilization of pinnipeds is challenging due to their extreme size, fierce attitude and fast reaction, this makes direct measurements of body mass problematic and potentially dangerous for the researcher, and additionally heavy equipment might be required (Boyd et al. 1993). Studies of mass loss and gain in female southern elephant seals, Mirounga leonina (L.), over the course of an annual cycle, has received little attention as a consequence of the logistical limitations associated with weighing these animals. Studies conducted at King George Island (Carlini et al. 1997, 1999), South Georgia (Boyd et al. 1993) and Macquarie Island (Hindell et al. 1994), relied on physically weighing and interacting with small numbers of animals.

Southern elephant seals have predictable haulout periods, high site fidelity and their naivety towards humans makes them excellent subjects for population demography studies. Southern elephant seals spend c. $85 \%$ of their lifetimes feeding in the pelagic environment (McIntyre et al. 2010), but haul out on land to breed, moult and overwinter (Kirkman et al. 2003, 2004). They fast throughout this period, relying exclusively on stored fat reserves for lactation (Arnbom et al. 1997). After breeding, females make a postlactation trip to sea, lasting a mean of $68.0 \pm 10.1$ days at Marion Island, to regain their mass before returning to shore for the annual obligatory moult.

We applied a simple mathematical mass estimation method on an established photogrammetry technique (de Bruyn et al. 2009) to calculate mass fluctuation over time. We investigate the applicability of it detecting mass fluctuations by comparing our results to other southern elephant seal populations. Implications for life history strategies of the female component are discussed. We evaluate the combined benefit of a long-term mark-recapture programme with photogrammetry in assessing individual mass change over a theoretically unlimited temporal scale. 


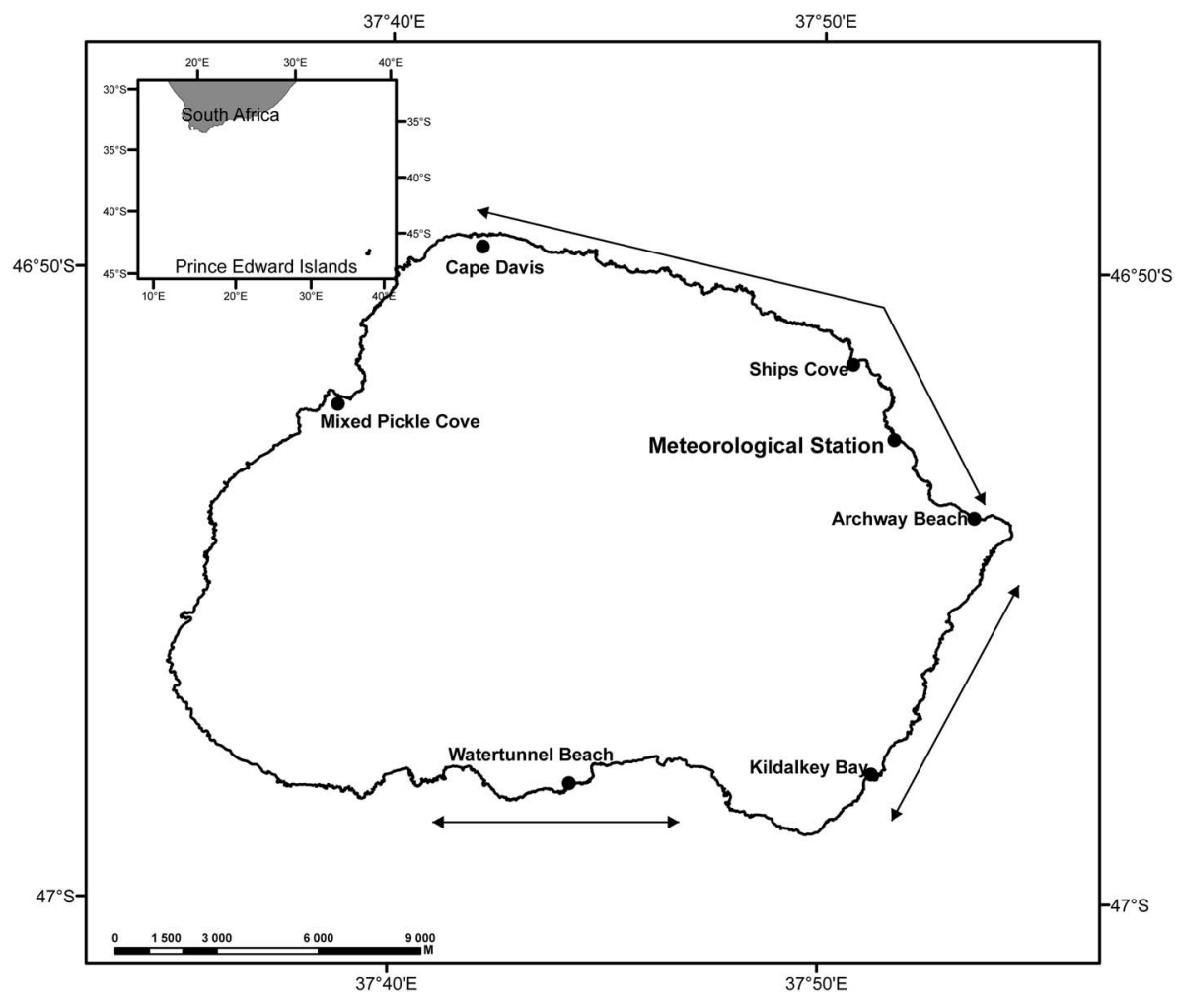

Fig. 1. Marion Island. Breeding period photogrammetry was performed between Ship's Cove and Archway Beach and all the beaches in the moult. The search for tagged seals along the coastline on all the beaches indicated with arrows, were conducted every seven days during the breeding season (mid-August to mid-November) and every ten days for the remainder of the year since 1983.

\section{Methods}

Study site

Marion Island $\left(46^{\circ} 54^{\prime} \mathrm{S}, 37^{\circ} 45^{\prime} \mathrm{E}\right)$, one of the two islands in the Prince Edward Islands is situated in the southern Indian Ocean. The coastline consists mainly of cliffs with pebble beaches on the eastern side of the island where elephant seals predominantly haul out (Condy 1978). For this study, a sequence of photographs of tagged (known-aged) breeding female southern elephant seals were taken at several breeding colony beaches between Ship's Cove and Archway Bay on the eastern aspect of the island (Fig. 1). On returning to the island for the moult haulout, the same females were photographed again.

\section{Tagging and mark-resighting programme}

Since 1983 practically all newly-weaned pups born on Marion Island were double tagged in each of their hind flippers with uniquely numbered, colour-coded Dalton

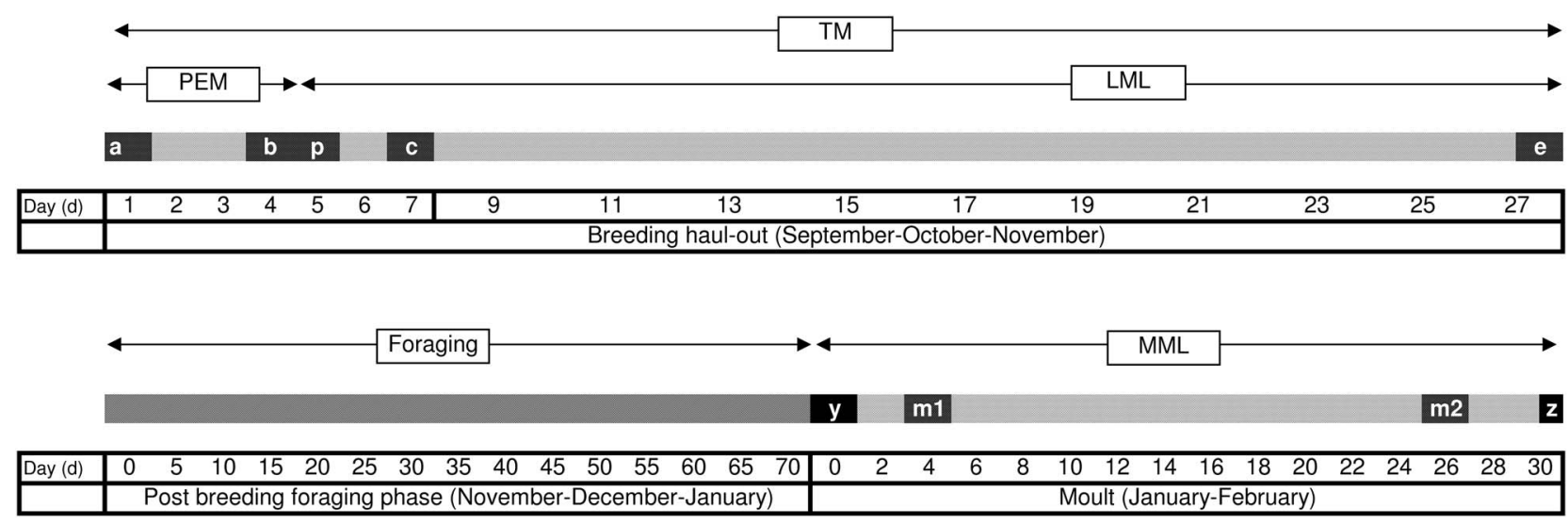

Fig. 2. Visual representation of annual female life cycle. $\mathrm{TM}=$ total mass loss in breeding haulout, $\mathrm{PEM}=$ pre-partum mass loss, $\mathrm{LML}=$ lactation mass loss. $\mathrm{a}=$ breeding season arrival photogrammetry $(\mathrm{PG})$ mass, $\mathrm{b}=$ pre-partum PG mass, $\mathrm{c}=$ post-partum PG mass, $\mathrm{d}=$ days elapsed, $\mathrm{e}=$ breeding season departure PG mass, $\mathrm{p}=$ partum. MML $=$ moult mass loss, $\mathrm{m} 1=$ first moult PG, $\mathrm{m} 2=$ second moult $\mathrm{PG}, \mathrm{y}=$ moult arrival mass, $\mathrm{x}=$ moult departure mass. 
jumbo tags (Dalton Supplies, Hendley-on-Thames, UK) as detailed by de Bruyn et al. (2008). Following tagging, all hauled out elephant seals were checked for the presence of tags on all popular beaches along the coastline (Fig. 1) every seven days during the breeding season (mid-August to mid-November) and every ten days for the remainder of the year. Tagged individuals were documented (tag number and cohort specific colour; sex if known; haulout site) to compile life history data for each individual.

\section{Photogrammetry}

Photogrammetry was performed with calibrated SLR (singlelens reflex) cameras (Canon 350D, 400D and 450D). Before the first time a camera is used for photogrammetry, each camera and lens combination is calibrated using a calibration grid with coded targets at a set focal length as described in the calibration manual in the Photomodeler Pro ${ }^{\circledR}$ (EOS systems Inc) software package. Importantly, the calibration procedure is performed for the minimum (in our case $=18 \mathrm{~mm}$ ) or maximum zoom setting to ensure repeatability of this setting in the field. The software requires a structured series of photographs, taking into account yaw (e.g. 90 degree rolls) and repeatable camera settings, to establish the relationship between lens and camera body (in the case of SLRs) or relevant parameters in compact cameras, to ensure that the entire field of view is calibrated. This effectively corrects for orthogonal distortion and conversion for the camera's entire field of view. Auto rotation, image stabilizer and red-eye settings of the camera were switched off for both calibration and field use to reduce unnecessary algorithm calculations/'noise' during processing. These precautions allow for optimal accuracy as stipulated in the Photomodeler ${ }^{\circledR}$ calibration procedure. In independent comparisons between several software packages and traditional calibration procedures, Photomodeler ${ }^{\circledR}$ calibration procedures were shown to be accurate and repeatable for close

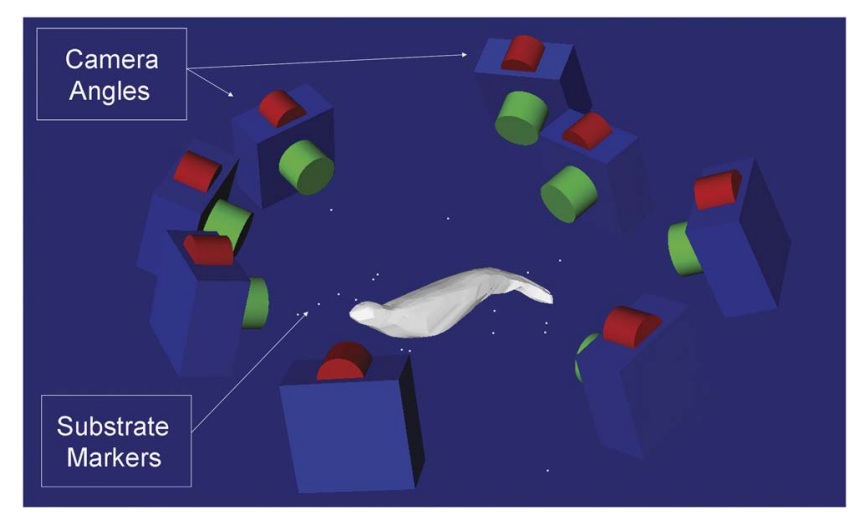

Fig. 3. Photomodeler ${ }^{\circledR}$ example: three-dimensional model of a female southern elephant seal used to estimate body mass. Substrate markers and camera positioning are indicated. range photogrammetry applications (Remondino \& Fraser 2006). During fieldwork, care was taken to ensure photos were taken at calibrated camera settings. Recalibration is only required if the camera or lens is bumped, otherwise badly damaged or rebuilt. As a matter of course, recalibration of already calibrated cameras is periodically performed to ensure photographic and calibration projects are matched, in the unlikely event that calibration settings are changed.

Eight or more photos were taken from different angles around a seal (subject) to form one project. Twenty-three female seals ranging from 3-18 years of age were repeatedly photographed between September 2009 and February 2010. For each of the animals, photogrammetric (PG) projects were performed: 1) upon their arrival for the breeding season, 2) post-partum to assess birthing mass loss for all mothers (Fig. 2), and 3) immediately pre-departure for their subsequent post-breeding pelagic foraging phase. Secondly, in the summer, photogrammetric projects were done during the moult following the post-breeding foraging trip: 1) pre-moult (or when animals were first sighted), and 2) post-moult, prior to seals departing for their post-moult pelagic phase. Three-dimensional models (based on each of the PG projects) (Fig. 3) were built using the de Bruyn et al. (2009) method for estimation of body mass. Volumetric estimation procedures were executed using the commercially available three-dimensional (3-D) modelling package Photomodeler Pro ${ }^{\circledR}$ version 6.2 (de Bruyn et al. 2009). From the digital photographs, a 3-D spatial model was created using fixed points on the substrate around the animal. These were cross-referenced between photographs to create a 3-D map of surrounding substrate. Mapping of the landmarks surrounding the subject attributes to the methods' robustness, as substrate markers remain unmoved between photographs, whereas living animals (the 'subject' in our case) are not absolutely unmoved between photographs (breathing, sneezing etc.). The silhouette (outline) of the animal was traced on all the photographs and cross-referenced between photographs to shape the model of the subject. The volume of the animal's shape was multiplied by a coefficient that is contingent on the mean total body density, the nature of the

Table I. Predictive equations to approximate body mass of southern elephant seals. Full view needs at least eight photos including all perpendicular and side angles. $\mathrm{PBM}=$ predicted body mass, $\mathrm{ME}=$ mass estimate from photogrammetric method $(\mathrm{kg})$ (with permission from de Bruyn et al. (2009)).

Model equation

Even substrate:

Full view

Missing one perpendicular

Missing an entire side view

$\mathrm{PBM}=\mathrm{ME}-[\mathrm{ME} \times(0.085 \pm 0.013)]$

$\mathrm{PBM}=\mathrm{ME}-[\mathrm{ME} \times(0.108 \pm 0.019)]$

$\mathrm{PBM}=\mathrm{ME}-[\mathrm{ME} \times(0.244 \pm 0.026)]$

Uneven substrate:

Full view

Missing one perpendicular

$\mathrm{PBM}=\mathrm{ME}-[\mathrm{ME} \times(0.006 \pm 0.027)]$

$\mathrm{PBM}=\mathrm{ME}-[\mathrm{ME} \times(0.004 \pm 0.038)]$

$\mathrm{PBM}=\mathrm{ME}-[\mathrm{ME} \times(0.099 \pm 0.034)]$ 
Table II. A summary of acronyms used in the study.

\begin{tabular}{ll}
\hline Acronym & Definition \\
\hline MI & Marion Island \\
KGI & King George Island \\
SG & South Georgia \\
MAQ & Macquarie Island \\
PG & Photogrammetry \\
SLR & Single-lense reflex \\
MAB & Mass immediately post-partum \\
MBB & Mass immediately pre-partum \\
PEM & Pre-partum mass loss \\
LML & Lactation mass loss \\
TM & Total mass loss \\
d & Days \\
MML & Moult mass loss \\
\hline
\end{tabular}

substrate upon which the animal is resting as well as the number of photographs in a project (table 2 in de Bruyn et al. 2009) to obtain an estimate of body mass (Table I). Consistency of body mass estimation was tested by performing two different projects of the same animal $(n=4)$ on the same day. Difference between projects ranged from $0.44-1.67 \%$ with a mean of $1.15 \pm 0.58 \% \mathrm{SD}$.

\section{Calculation of date of birth, and pre- and post-partum mass}

Daily observations along the coastal study area allowed determination of the exact weaning date for all pups, as well as the concomitant departure date for all mothers, in order to calculate the mean duration of suckling. Repeated daily observations allowed a linear time model to be created, from which we could calculate exact time of weaning and mother departure (the two are not always the same, but mostly they are). Using linear time model mean suckling duration, timing of PG projects and censuses could be used to calculate the date of birth from weaning date for each individual.

Pre- and post-partum PG projects were performed to assess birthing mass loss for all mothers (Fig. 3). Thirteen females were photographed on arrival. Of these, six females were also photographed immediately pre-partum and pre-departure. The remaining females' arrival mass was estimated by multiplying the calculated mean daily mass loss pre-partum from the 13 females (with arrival PG) with days elapsed between arrival and birth. Additionally, daily mass loss between post-partum PG mass estimates and pre-departure PG mass estimates were calculated from 16 females that all had both a post-partum PG and a pre-departure PG mass estimate. Where post-partum PG projects could not be done immediately following parturition, mean daily post-partum mass loss (as calculated from the above 16 females) was multiplied with number of days between post-partum PG and date of birth to obtain estimated mass at the start of lactation (MAB, Table II).

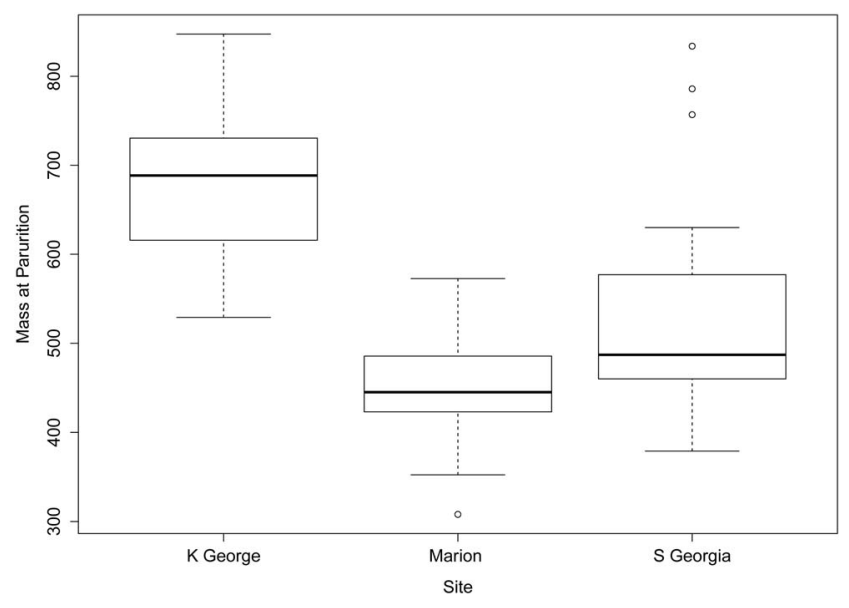

Fig. 4. Mass comparison at the start of lactation between female southern elephant seals from Marion Island, King George Island ( $n=12$ (Carlini et al. 1997)) and South Georgia $(n=27$ (Fedak et al. 1996)).

Similar mass loss rates in pre-partum (mean $=3.8 \pm 1.7 \mathrm{~kg}$ ) and post-partum (mean $=7.0 \pm 2.9 \mathrm{~kg})$ between six individuals with photogrammetry at arrival, immediately post-partum and pre-departure supports our assumption of using mean mass loss rate in calculation of mass at specific instances for those females where a particular PG was missing. A mean of $34.1 \mathrm{~kg}$ for female pups and $40.3 \mathrm{~kg}$ for male pups (Wilkinson \& Van Aarde 2001) and a placenta mass of $3.5 \mathrm{~kg}$ (Arnbom et al. 1997) were added to estimate mass just before birth (MBB). If pup sex was unknown $(n=4)$, a mean value of $37.2 \mathrm{~kg}$ was used. Twelve females were photographed on the day of departure, the remaining females' departure mass was estimated by multiplying the calculated mean mass loss per day (post-partum) with the days elapsed between departure and previous $\mathrm{PG}$.

\section{Breeding haulout equations}

Pre-partum mass loss (PEM), lactation mass loss (LML) and absolute mass loss (TM) were calculated for each female using the following equations:

$$
\begin{gathered}
P E M=\text { Mass }_{\text {arrival }}-\text { Mass }_{\text {pre_partum }} . \\
L M L=\text { Mass }_{\text {birth }}-\text { Mass }_{\text {departure }} . \\
T M=\text { Mass }_{\text {arrival }}-\text { Mass }_{\text {departure }}
\end{gathered}
$$

Daily mass loss rates for the pre-partum period were calculated for animals that had arrival PG mass estimates $(n=13)$ using the following equation:

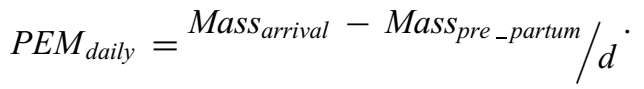




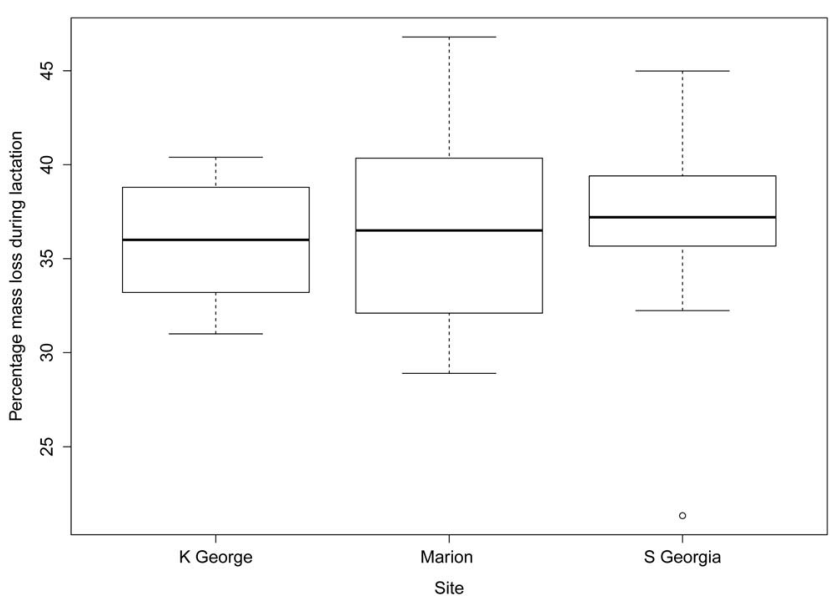

Fig. 5. Percentage mass loss during the lactation period for female southern elephant seals from Marion Island, King George Island and South Georgia.

Daily mass loss rates for the post-partum period were calculated for animals with post-partum and departure PG mass estimates $(n=16)$ using the following equation:

$$
L M L_{\text {daily }}=\text { Mass }_{\text {post_partum }}-\text { Mass }_{\text {departure }} / d .
$$

In order to calculate the amount of mass loss as a result of parturition, the difference between mass directly after and before parturition was measured. Daily mass loss rates were used to calculate the mass of female southern elephant seals directly after parturition using the following equation:

$$
\text { Mass }_{\text {after_birth }}=\text { Mass }_{\text {post_partum }}+\left(d \times L M L_{\text {daily }}\right) \text {. }
$$

Pup mass and placenta mass were added to obtain mass estimates directly before birth (as described earlier). If no post-partum PG mass estimates were available, mass directly before birth was estimated from arrival PG mass estimates as:

$$
\text { Mass }_{\text {before _birth }}=\text { Mass }_{\text {arrival }}-\left(d \times P E M_{\text {daily }}\right) .
$$

If mass before birth was obtained as described in Eq. (7), pup mass (Wilkinson \& Van Aarde 2001) and placenta mass (Arnbom et al. 1997) was subtracted to obtain mass after birth.

\section{Moult haulout equations}

Moult mass loss (MML), was calculated for each female using the following equation:

$$
M M L=\text { Mass }_{\text {arrival }}-\text { Mass }_{\text {departure }} .
$$

Daily mass loss rates for the moult period were calculated for animals that had both post arrival - and pre-departure PG mass estimates $(n=13)$ using the following equation:

$$
M M L_{\text {daily }}=\text { Mass }_{\text {post_arrival }}-\text { Mass }_{\text {pre_departure }} / d .
$$

\begin{tabular}{|c|c|c|c|}
\hline & $\begin{array}{c}\text { Marion Island }^{\circ} \\
2009 / 2010 \\
\text { Mean } \pm \text { SD }\end{array}$ & $\begin{array}{c}\text { Breeding haulout } \\
\text { South Georgia }{ }^{2} \\
1986 \& 1988 \\
\text { Mean } \pm \text { SD }\end{array}$ & $\begin{array}{c}\text { King George }^{1} \\
1994 / 1995 \\
\text { Mean } \pm \text { SD }\end{array}$ \\
\hline Post-partum mass (kg) & $453.2 \pm 63.9$ & $515 \pm 100$ & $678.6 \pm 96$ \\
\hline Duration of lactation (days) & $22.6 \pm 2.1$ & $23.3 \pm 2.2$ & $22.7 \pm 1.9$ \\
\hline Mass loss $(\mathrm{kg})$ & $165.7 \pm 31.3$ & $191 \pm 36$ & $242.4 \pm 31.4$ \\
\hline Percentage mass loss during lactation (\%) & $36.6 \pm 5.1$ & $37.1 \pm 4.1$ & $35.9 \pm 3.9$ \\
\hline Foraging duration (days) & $68 \pm 10.7$ & $P=0.01$ & $60.5 \pm 6.2$ \\
\hline Mass gained $(\mathrm{kg})$ & $155.83 \pm 32.42$ & $P=0.07$ & $132.2 \pm 35.6$ \\
\hline
\end{tabular}

Table III. Breeding seasons from Marion Island 2009/10, King George Island 1994/95 and South Georgia 1986 and 1988 are compared on the basis of post-partum mass $(\mathrm{kg})$, duration of lactation (days), mass loss $(\mathrm{kg})$ and percentage lactation mass loss (\%). Similarly, post-breeding foraging phases are compared on basis of foraging duration (days), mass gained $(\mathrm{kg})$, rate of mass gain $\left(\mathrm{kg} \mathrm{day}^{-1}\right)$ and percentage mass gained during post-breeding foraging phase (\%). Values for post-breeding foraging for Macquarie Island were not available.

${ }^{\circ}$ This study, ${ }^{1}$ Carlini et al. $1997,{ }^{2}$ Fedak et al. 1996. 


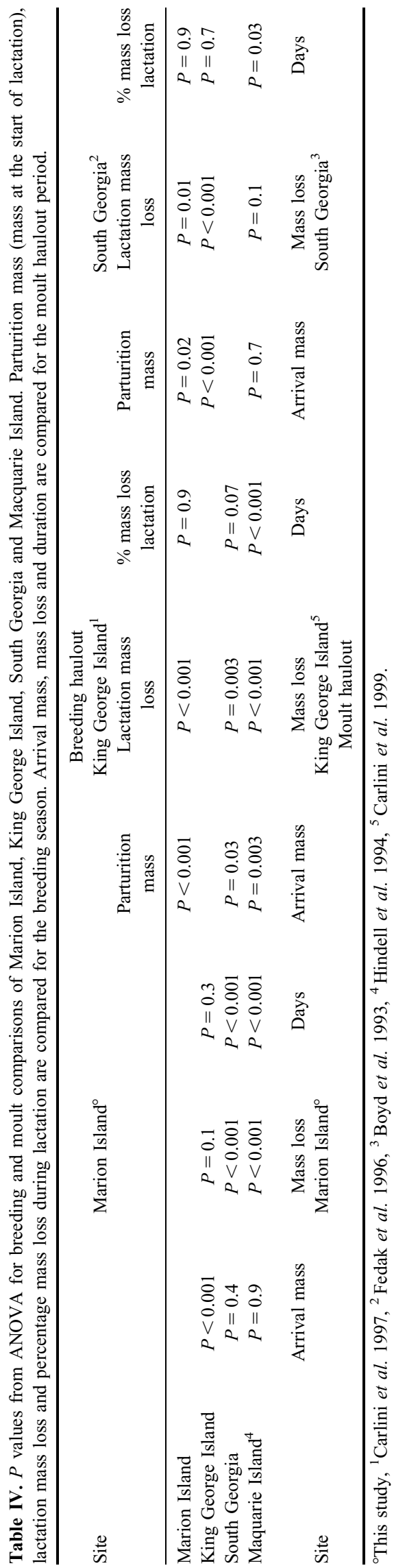

The duration of the post-breeding foraging phase and the moult durations were obtained through the continuous mark-resighting programme associated with the ten day resighting cycle (Fig. 1). Due to the nature of the moult haulout and the ten day resighting cycle a mean moult duration was applied to animals that arrived and departed between sightings to obtain moult arrival and departure mass, using the following equations:

$$
\begin{gathered}
\text { Mass }_{\text {arrival }}=\text { Mass }_{\text {post_arrival }}+\left(d \times M M L_{\text {daily }}\right) . \\
\text { Mass }_{\text {departure }}=\text { Mass }_{\text {pre_departure }}-\left(d \times M M L_{\text {daily }}\right) .
\end{gathered}
$$

Similarly a mean mass loss per day was used for animals that did not have an individual mass loss per day recorded due to a lack of two photogrammetry projects.

\section{Statistical analysis}

The program R version 2.13.1 (R Development Core Team 2011) was used for statistical analysis. Breeding and moult data from different islands were compared statistically using an ANOVA and post hoc TukeyHSD test. Normality was tested using a Shapiro-Wilks test, and if absent, data was $\log$ transformed. Mass loss per day in the moult was statistically compared using Kruskal-Wallis test. A $t$-test was used for post-breeding foraging duration comparison. Significance was set at $P<0.05$.

\section{Results}

\section{Breeding period}

Comparisons between female southern elephant seals from Marion Island (MI) $n=23$, King George Island (KGI) $n=12$ and South Georgia (SG) $n=27$ focussed on: post-partum mass (Fig. 4), duration of lactation, absolute and percentage mass loss during the lactation period (calculated from postpartum mass) (Fig. 5) (Table III) for females aged 3-18 years. Mass after parturition from MI differed significantly $(P<0.001)$ from KGI and from SG $(P=0.02)$ (Table IV). Lactation mass loss significantly differed from KGI $(P<0.001)$ and SG $(P=0.01)$. Percentage mass loss during the course of lactation from MI did not differ from KGI $(P=0.9)$ or SG $(P=0.9)$ (Table IV). Post-partum mass loss per day $\left(\right.$ mean $\left.=7.5 \pm 2.3 \mathrm{~kg} \mathrm{day}^{-1}\right)$ was similar to the South Georgia population $\left(\right.$ mean $=7.9 \pm 1.4 \mathrm{~kg}$ day $\left.^{-1}\right)$.

\section{Post-breeding pelagic foraging period}

Female pelagic foraging aspects that were compared between populations were: time spent foraging, absolute mass gained, rate of mass gain and percentage mass gained (Table III). Time spent at sea for MI individuals ranged from 48-92 days (mean $=68 \pm 10.7$ days). King George Island females ranged from 51-71 days 
Table V. Comparison of four different female southern elephant seal populations during the moult. Comparison was made between initial mass when females arrived, duration of the moult, mass loss per day and total mass.

\begin{tabular}{|c|c|c|c|c|}
\hline & $\begin{array}{c}\text { Marion Island }^{\circ} \\
\text { Mean } \pm \text { SD }\end{array}$ & $\begin{array}{c}\text { King George }^{1} \\
\text { Mean } \pm \text { SD }\end{array}$ & $\begin{array}{l}\text { South Georgia }^{2} \\
\text { Mean } \pm \text { SD }\end{array}$ & $\begin{array}{l}\text { Macquarie }^{3} \\
\text { Mean } \pm \text { SD }\end{array}$ \\
\hline Initial mass at moulting $(\mathrm{kg})$ & $443 \pm 61$ & $567 \pm 73$ & $483 \pm 86$ & $447 \pm 69$ \\
\hline Time (days) & $30.4 \pm 6.8$ & $25.7 \pm 4.3$ & $21.0 \pm 4.4$ & $16.8 \pm 3.1$ \\
\hline Total mass loss (kg) & $150 \pm 27$ & $129 \pm 22$ & $94 \pm 25$ & $73 \pm 18$ \\
\hline$n$ & 23 & 9 & 19 & 13 \\
\hline
\end{tabular}

${ }^{\circ}$ This study, ${ }^{1}$ Carlini et al. 1999, ${ }^{2}$ Boyd et al. 1993, ${ }^{3}$ Hindell et al. 1994.

(mean $=60.5 \pm 6.2$ ) with $T_{(-2.7)}=32, P=0.01$ (Table III). Mass gain in the post-breeding foraging phase for MI ranged from $119.3-261.3 \mathrm{~kg}($ mean $=155.8 \pm 32.4 \mathrm{~kg})$ and KGI ranged from $94.0-204.0 \mathrm{~kg}$ (mean $=132 \pm 35.6 \mathrm{~kg})$ with $T_{(-1.9)}=20.6, \quad P=0.07 \quad$ (Table III). Percentage lactation mass recovery for MI females ranged from 50.1 to $167.5 \%$ (mean $=97.7 \pm 27.9 \%$ ) of mass lost in the lactation period.

\section{Moult period}

The initial moult haulout mass, duration of the moult, total mass loss and mass loss per day for the obligatory moult phase at MI were compared to KGI, SG and Macquarie Island (MAQ) (Table V). Total mass loss for the duration of the moult ranged from $102.1-233.1 \mathrm{~kg}$ (mean $=150 \pm 27 \mathrm{~kg}$, Table V). Moult arrival mass from MI is significantly different $(P<0.001)$ from KGI and is similar to SG $(P=0.4)$ and MAQ $(P=0.9)$ (Table V). Mass loss during the moult from MI significantly differs from SG and MAQ $(P<0.001)$ but MI and KGI do not differ $(P=0.1)$. Similar results were found for moult duration, where MI significantly differs from $\mathrm{SG}$ and MAQ $(P<0.001)$ but MI and KGI do not differ $(P=0.3)$ (Table IV).

\section{Discussion}

\section{Photogrammetry effectiveness over a temporal scale}

Percentage mass loss during the lactation period for KGI is similar to SG (McCann et al. 1989, Fedak et al. 1994, Carlini et al. 1999) and indicates that females lose c. $35 \%$ of their mass during lactation. Similar percentage lactation mass loss among populations would indicate that there are set physiological limitations devoted to lactation. No significant differences were found between percentage mass loss from the geographically separated populations at MI, KGI and SG with percentage mass loss apparently a constant in the species (e.g. McCann et al. 1989, Le Boeuf \& Laws 1994, Fedak et al. 1996, Arnbom et al. 1997, Carlini et al. 1997, 1999, this study). Although females from MI are smaller in absolute size (this study) their percentage mass loss is similar to those of KGI and SG. These results indicate that photogrammetric mass estimation can be used alongside datasets of physically weighed animals for comparative studies. Photogrammetry is an effective method for measuring and comparing mass change of female southern elephant seals over time. Of all photogrammetry projects done, $91.5 \%$ solved accurately (following the 'accuracy checking' procedure outlined in de Bruyn et al. (2009)), even though PG was done in various environments, ranging from flat sandy beaches, undulating boulder beaches, grassy Cotula areas and moult wallows (present study). Over 1000 projects have been performed since 2006 during which time the field method was improved to make analysis easier and less time consuming. Currently, the method is fast and efficient and multiple projects can be done on one day whilst collecting a multitude of other data. Less than $10 \%$ of photogrammetric projects failed due to environmental and photographic limitations. Through photogrammetric mass estimation on specific individuals, a longitudinal database can be established.

\section{Spatial variation in female southern elephant seal mass}

Numerous studies have investigated lactation parameters (e.g. McCann et al. 1989, Le Boeuf \& Laws 1994, Fedak et al. 1996, Arnbom et al. 1997, Carlini et al. 1997, 1999, McMahon et al. 2000) and thus it is the logical starting point to compare separate populations in the breeding season and the first step to validation of the analytical mass estimation over time. The mean duration of lactation does not differ significantly between populations $(P=0.8)$. Females spend c. 23 days suckling their young (Table III). However, female mass after parturition differs greatly between MI, KGI and SG. Females from MI are $c$. $200 \mathrm{~kg}$ lighter at the beginning of lactation than their counterparts at KGI and c. $60 \mathrm{~kg}$ lighter than females from SG (present study). Females from KGI and SG are larger at arrival. Larger size is advantageous in terms of the amount of energy available for lactation (Carlini et al. 2004). Similarly absolute lactation mass loss for female southern elephant seals from MI is significantly different from those at KGI and SG. This is not surprising as females from KGI and SG are significantly larger than MI 
females at the start of lactation (this study). Females from MI lose c. $80 \mathrm{~kg}$ less mass than their counterparts on KGI and c. $30 \mathrm{~kg}$ less than females from SG (present study). Greater absolute energy loss from larger females is positively related to greater energy gain by their pup (Carlini et al. 2004). Pups are dependent on the mass acquired by a female during foraging to grow and successfully wean. In addition, the greater the weaning mass of southern elephant seal pups the higher the probability of survival (McMahon et al. 2000, 2003). Female size and reserves at parturition proved to be the most significant factors determining pup mass gain in large phocid seals (e.g. Fedak et al. 1996).

Smaller marine mammals spend less time submerged and less time foraging at any given depth (Hindell et al. 2000). The ability to forage for longer periods at depth would be advantageous for resource acquisition and mass gain. In addition, smaller individuals will have a higher mass specific metabolic rate than larger individuals (Kleiber's law, Kleiber 1947). The higher mass specific metabolic rate for females at MI compared to larger females from KGI and SG could in extreme cases lead to smaller individuals adopting different feeding strategies or focus on different prey species (e.g. Hindell et al. 2000). The mass acquired in aquatic foraging is a good indication of the availability of food on feeding grounds and the success of female foraging (Boyd \& McCann 1989).

Historically sealing threatened southern elephant seal population numbers more than food availability. In the previous centuries, southern elephant seals were exploited for their oil which diminished their numbers drastically (Laws 1994). After 1964 when sealing was stopped, the South Georgia and Peninsula Valdes southern elephant seal populations either remained stable or increased (Boyd \& Croxall 1996). While SG and KGI populations increased or stabilized others decreased, $83 \%$ for MI (Pistorius et al. 2011), and $57 \%$ for MAQ (Laws 1994). The availability of prey has often been hypothesized to be the main factor determining population status in the MI and MAQ populations (Hindell et al. 1994, Pistorius et al. 2011). The drastic decline in MI population size since the 1950s (McMahon et al. 2005) may be attributed to the anthropomorphic disturbance caused by sealing in the 1800s and early 1900s (Richards 1992) and possibly the prolonged illegal fisheries in the area around the island before the establishment of the exclusive economic zone in 1996 (Pakhomov \& Chown 2003).

Such long-term resource exploitation could stunt growth (Trites \& Donnelly 2003). Such large-scale events may cause the reduction in body size of an entire generation and have potential long-term consequences for female body size (Huston \& Wolverton 2011). A recent study of polar bears (Ursus maritimus Phipps) in Alaska has shown a decrease in offspring skull and body length as well as body size in years of reduced sea ice (prey availability) (Rode et al. 2010). Similar findings were found in Steller sea lions (Eumetopias jubatus Schreber) with reduced body size and body condition due to a lower nutritional plane (Rosen 2009). On the contrary, high food availability per animal is paramount in determining adult body size and can allow high population growth rates (e.g. fecundity and survival) (Huston \& Wolverton 2011). It is presumed that the more stable Atlantic southern elephant seal population is in some way connected to more abundant resources (Vergani et al. 2001). Thus KGI (stable) and SG (stable) (McMahon et al. 2005) populations presumably have higher food availability per capita as compared to the smaller MI females (previously declining).

The nutritional stress hypothesis may explain this phenomenon. It states that a negative physiological or behavioural state (e.g. reduced body size or productivity) emerges due to low quantity or quality food availability for animals (Trites \& Donnelly 2003). The global population declined between 1950 and 1990 (Laws 1994) and the physiologically smaller female body size (this study) as well as the behavioural modification of females skipping breeding seasons (de Bruyn et al. 2011) at MI, all indicate a scenario that can be explained by the nutritional stress hypothesis. Significantly longer foraging in the post-breeding foraging phase supports this hypothesis. The variation could be due to differences in prey availability between respective foraging grounds. Females from KGI travel to the area west of the Antarctic Peninsula (McConnell \& Fedak 1996, Bornemann et al. 2000) and MI females travel predominantly to the south and south-west of the island (McIntyre et al. 2010). The difference between the two post-breeding foraging phases is about eight days (Table III). KGI is less than one day's travel from some highly productive areas west of the Antarctic Peninsula (McConnell \& Fedak 1996, Bornemann et al. 2000), whereas it could take females at MI three or four days to "commute" to their feeding areas south and southwest of the island (McIntyre et al. 2010). Percentage mass gain in the post-breeding foraging phase was also significantly higher for MI females than those at KGI $(P<0.001)$. The higher percentage of lactation mass regained for MI could be attributed to extended post-breeding foraging duration and the smaller size of females at MI. As there is no significant difference in rate of mass gain between MI females and their counterparts on KGI $(P=0.6)$ and females from MI spend more time foraging, absolute mass gain at the latter island should be greater. On the contrary, absolute mass gain between MI and KGI did not differ significantly $(P=0.07)$.

Following the post-breeding foraging phase, females return for the moult. At arrival females from MI weigh c. $80 \mathrm{~kg}$ less than those from KGI and c. $40 \mathrm{~kg}$ less than those at SG. Perhaps unsurprisingly, females from MI did not differ significantly from those at MAQ that also experienced prolonged population decline (Laws 1994). Females from MI arrive for both terrestrial haulouts with a lower mass than their counterparts at KGI and SG. It appears that the mass loss in the moulting period on $\mathrm{MI}$ is similar to that of the mass loss during the lactation period, 
contrary to findings for other populations. The smaller size and the relatively similar absolute mass gain in the post-breeding foraging phase compared to larger females elsewhere, implies larger percentage mass gain at MI.

Due to differences in the observed time spent ashore for MI and KGI compared to MAQ and SG (probably because of sampling artefacts rather than the actual time spent ashore) we dismissed the comparison of moult duration. For females from SG (Boyd et al. 1993) and MAQ (Hindell et al. 1994) it is difficult to obtain an exact time spent ashore as females were either unmarked and/or observations are infrequent, while the relatively small size of MI as well as the ongoing extensive mark-resighting programme facilitates calculation of the approximate duration of the moult (Kirkman et al. 2003). Rate of mass gain $\left(\right.$ mean $\left.=2.34 \pm 0.56 \mathrm{~kg} \mathrm{day}^{-1}\right)$ in the postbreeding pelagic foraging phase is approximately similar between populations, which poses the question of why female body mass at the end of parturition differs so greatly? Perhaps a clue is evident in the observed difference in population trajectories between KGI, SG (stable/increasing) and MI (previously declining). Prey availability per individual has probably increased which is evident in the increase in weaning mass (McMahon et al. 2003), larger percentage mass gain in post-breeding foraging phase (this study) and recent population stabilization at MI (Pistorius et al. 2011), which is indicative of a recovering population. Weaning mass is a function of maternal energy reserves which females acquire in their pelagic foraging bouts (Vergani et al. 2001), therefore an increase in weaning mass provides a potentially useful indicator of prey availability and subsequently maternal energy reserves (Vergani et al. 2008). Furthermore, variation in body size within a species does occur. Individuals in cooler or higher latitudes are larger than individuals in lower and warmer latitudes (Bergmann's rule, Bergmann 1847). Under this hypothesis, southernmost populations of southern elephant seals are predisposed to larger size.

In conclusion, accurately measuring mass of southern elephant seal females throughout both terrestrial phases in the annual cycle enabled us to confirm the effectiveness of photogrammetry over a temporal scale. Mass change of individuals within the MI population could be explored and compared to other populations. Females from MI are smaller than their counterparts on KGI and SG, but have the same relative percentage mass loss during lactation compared to other populations. Smaller size may be due to a prolonged population decline as a result of anthropogenic disturbance or climate effect on prey availability. The smaller size of MI females could affect their reproductive and survival success.

\section{Acknowledgements}

We thank the South African Department of Environmental Affairs for providing logistical support within the South
African National Antarctic Programme and the Department of Science and Technology (administered through the National Research Foundation) for funding the marine mammal monitoring programme at Marion Island. The Marion Island seal researchers of 2006, 2007, 2008 and 2009 are thanked for their endless hours of data collection and Cheryl Tosh for valuable comments on earlier versions of this paper. The comments by the editor and two anonymous reviewers are acknowledged and improved the manuscript.

\section{References}

Arnbom, T.R., FedaK, M.A. \& Boyd, I.L. 1997. Factors affecting maternal expenditure in southern elephant seals during lactation. Ecology, 78, 471-483.

BAKER, W.H. 1960. Elements of photogrammetry. New York: Ronald Press, 199 pp.

Bergmann, C. 1847. Über die Verhältnisse der Warmeokonomie der Tiere zu ihrer Grosse. Göttinger Studien, 3, 595-708.

Bornemann, H., Kreyscher, M., Ramdorhr, S., Martin, T., Carlini, A., Sellmann, L. \& Plötz, J. 2000. Southern elephant seal movement and Antarctic sea ice. Antarctic Science, 12, 3-15.

Boyd, I.L. \& Croxall, L.P. 1996. Dive durations in pinnipeds and seabirds. Canadian Journal of Zoology, 74, 1696-1705.

Boyd, I.L. \& McCANN, T.S. 1989. Prenatal investment in reproduction by female Antarctic fur seals. Behavioural Ecology and Sociobiology, 24, 377-385.

Boyd, I.L., Arnbom, T.R. \& Fedak, M.A. 1993. Water flux, body composition, and metabolic rate during moult in female southern elephant seals (Mirounga leonina). Physiological Zoology, 66, 43-60.

Carlini, A.R., Marquez, M.E.I., Daneri, G.A. \& Poljak, S. 1999. Mass changes during their annual cycle in females of southern elephant seals at King George Island. Polar Biology, 21, 234-239.

Carlini, A.R., Daneri, G.A., Marquez, M.E.I., Soave, G.E. \& Poljak, S. 1997. Mass transfer from mothers to pups and mass recovery by mothers during the post-breeding foraging period in southern elephant seals (Mirounga leonina) at King George Island. Polar Biology, 18, 305-310.

Carlini, A.R., Marquez, M.E.I., Panarello, H., Ramdohr, S., Daneri, G.A., Bornemann, H. \& Plötz, J. 2004. Lactation costs in southern elephant seals at King George Island, South Shetland Islands. Polar Biology, 27, 266-276.

Condy, P.R. 1978. The distribution and abundance of southern elephant seals Mirounga leonina (Linn.) on the Prince Edward Islands. South African Journal of Antarctic Research, 8, 42-48.

De Bruyn, P.J.N., Bester, M.N., Carlini, A.R. \& Oosthuizen, W.C. 2009. How to weigh an elephant seal with one finger: a simple threedimensional photogrammetric application. Aquatic Biology, 5, 31-39.

De Bruyn, P.J.N., Tosh, C.A., Oosthuizen, W.C., Phalanndwa, M.V. \& BESTER, M.N. 2008. Temporary marking of unweaned southern elephant seal (Mirounga leonina L.) pups. South African Journal of Wildlife Research, 38, 133-137.

De Bruyn, P.J.N., Tosh, C.A., Bester, M.N., Cameron, E.Z., McIntyre, T. \& Wilkinson, I.S. 2011. Sex at sea: alternative mating system in an extremely polygynous mammal. Animal Behaviour, 82, 445-451.

FedAK, M.A., ArnBom, T. \& Boyd, I.L. 1996. The relation between the size of southern elephant seal mothers, the growth of their pups, and the use of maternal energy, fat, and protein during lactation. Physiological Zoology, 69, 887-911.

Fedak, M.A., Arnbom, T.A., McConnell, B.J., Chambers, C., Boyd, I.L., Harwood, J. \& McCANn, T.S. 1994. Expenditure, investment, and acquisition of energy in southern elephant seals. In LE BoEUF, B.J. \& LAws, R.M., eds. Elephant seals: population ecology, behaviour, and physiology. Berkeley, CA: University of California Press, 354-373. 
Hindell, M.A., Slip, D.J. \& Burton, H.R. 1994. Body mass loss of moulting female southern elephant seals, Mirounga leonina, at Macquarie Island. Polar Biology, 14, 275-278.

Hindell, M.A., Lea, M.A., Morrice, M.G. \& McMahon, C.R. 2000. Metabolic limits on dive duration and swimming speed in the southern elephant seal Mirounga leonina. Physiological and Biochemical Zoology, 73, 790-798.

Huston, M.A. \& Wolverton, S. 2011. Regulation of animal size by eNPP, Bergmann's rule, and related phenomena. Ecological Monographs, 81, 349-405.

Kirkman, S.P., Bester, M.N., Hofmeyr, G.J.G., Jonker, F.C., Pistorius, P.A., Owen, R. \& Strydom, N. 2004. Variation in the timing of the breeding haulout of female southern elephant seals at Marion Island. Australian Journal of Zoology, 52, 379-388.

Kirkman, S.P., Bester, M.N., Pistorius, P.A., Hofmeyr, G.J.G., Jonker, F.C., Owen, R. \& Strydom, N. 2003. Variation in the timing of moult in Southern Elephant seals at Marion Island. South African Journal of Wildlife Research, 33, 79-84.

KLeIBER, M. 1947. Body size and metabolic rate. Physiological Review, 27, $511-541$.

LAws, R.M. 1994. History and present status of southern elephant seal populations. In Le Boeuf, B.J. \& Laws, R.M., eds. Elephant seals: population ecology, behaviour and physiology. Berkeley, CA: University of California Press, 49-65.

Le Boeuf, B.J. \& Laws, R.M. 1994. Elephant seals: population ecology, behaviour and physiology. Berkeley, CA: University of California Press, $414 \mathrm{pp}$.

Lebreton, J., Burnham, K.P., Clobert, J. \& Anderson, D.R. 1992. Modelling survival and testing biological hypotheses using marked animals: a unified approach with case studies. Ecological Monographs, 62, 67-118.

McCann, T.S., FedaK, M.A. \& Harwood, J. 1989. Parental investment in southern elephant seals, Mirounga leonina. Behavioural Ecological and Sociobiology, 25, 81-87.

McConnell, B.J. \& FedAK, M.A. 1996. Movements of southern elephant seals. Canadian Journal of Zoology, 74, 1485-1496.

McIntyre, T., De Bruyn, P.J.N., Ansorge, I.J., Bester, M.N., Bornemann, H., Plötz, J. \& Tosh, C.A. 2010. A lifetime at depth: vertical distribution of southern elephant seals in the water column. Polar Biology, 33, 1037-1048.

McMahon, C.R., Burton, H.R. \& Bester, M.N. 2000. Weaning mass and the future survival of southern elephant seals, Mirounga leonina, at Macquarie Island. Antarctic Science, 12, 149-153.
McMahon, C.R., Burton, H.R. \& Bester, M.N. 2003. A demographic comparison of two southern elephant seal populations. Journal of Animal Ecology, 72, 61-73.

McMahon, C.R., Bester, M.N., Burton, H.R., Hindell, M.A. \& Bradshaw, C.J.A. 2005. Population status, trends and a re-examination of the hypotheses explaining the recent declines of the southern elephant seal Mirounga leonina. Mammal Review, 35, 82-100.

Pакномоv, Е.A. \& Chоwn, S.L. 2003. The Prince Edward Islands: Southern Ocean oasis. Ocean Yearbook, 17, 348-379.

Pistorius, P.A., De Bruyn, P.J.N. \& Bester, M.N. 2011. Population dynamics of southern elephant seals: a synthesis of three decades of demographic research at Marion Island. African Journal of Marine Science, 33, 523-534.

R Development Core Team. 2011. R: a language and environment for statistical computing. Vienna: Wirtschafts Universität, http://www. R-project.org.

Remondino, F. \& Fraser, C. 2006. Digital camera calibration methods: consideration and comparisons. International Archives of Photogrammetry, Remote Sensing and Spatial Information Sciences, 36, 266-272.

RichARDS, R. 1992. The commercial exploitation of sea mammals at Iles Crozet and Prince Edward Islands before 1850. Polar Monographs, 1, $1-19$.

Rode, K.D., Amstrup, S.C. \& Regehr, E.V. 2010. Reduced body size and cub recruitment in polar bears associated with sea ice decline. Ecological Application, 20, 768-782.

Rosen, D.A.S. 2009. Steller sea lions Eumetopias jubatus and nutritional stress: evidence from captive studies. Mammal Review, 39, 284-306.

Trites, A.W. \& Donnelly, C.P. 2003. The decline of Steller sea lions Eumetopias jubatus in Alaska: a review of the nutritional stress hypothesis. Mammal Review, 33, 3-28.

Vergani, D.F., Stanganelli, Z.B. \& Bilenca, D. 2001. Weaning mass variation of southern elephant seals at King George Island and its possible relationship with "El Niño" and "La Niña" events. Antarctic Science, 13, 37-40.

Vergani, D.F., Labraga, J.C., Stanganelli, Z.B. \& Dunn, M. 2008. The effects of El Niño-La Niña on reproductive parameters of elephant seals feeding in the Bellingshausen. Journal of Biogeography, 35, 248-256.

WILKINSON, I.S. \& VAN AARDE, R.J. 2001. Investment in sons and daughters by southern elephant seals, Mirounga leonina, at Marion Island. Marine Mammal Science, 17, 873-887. 